NASA Technical Memorandum 102565

ICOMP-90-11

Fiber Pushout Test: A Three-

Dimensional Finite Element

Computational Simulation

Subodh K. Mital

Institute for Computational Mechanics in Propulsion

Lewis Research Center

Cleveland, Ohio

and

Christos C. Chamis

Lewis Research Center

Cleveland, Ohio

$\Rightarrow$ (NASA-TM-10?565) FIOER PUSHUUT T=ST:A

THREE-LIMENSIONAL FINITE ELFMENT

COMPUTATIONAL SIMULATION (NASA) IP $P$

CSCL $110 \quad$ Unclas

GS/L4 0277020

- April 1990 


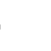




\title{
FIBER PUSHOUT TEST: A THREE-DIMENSIONAL FINITE ELEMENT
}

COMPUTATIONAL SIMULATION

\author{
Subodh K. Mital* \\ Institute for Computational Mechanics in Propulsion \\ Lewls Research Center \\ Cleveland, Oh10 44135
}

and

Christos C. Chamist

National Aeronautics and Space Administration

Lewis Research Center

Cleveland, Ohio 44135

0
0
0
$m$
$i$
$w$
$w$

\begin{abstract}
SUMMARY
A fiber pushthrough process has been computationally simulated using three-dimensional finite element method. The interface material is replaced by an anisotropic material with greatly reduced shear modulus in order to simulate the flber pushthrough process using a linear analysis. Such a procedure is easily implemented and is computationally very effective. It can be used to predict fiber pushthrough load for a composite system at any temperature. The average interface shear strength obtained from pushthrough load can easily be separated into its two components: one that comes from frictional stresses and the other that comes from chemical adhesion between fiber and the matrix and mechanical interlocking that develops due to shrinkage of the composite because of phase change during the processing. Step-by-step procedures are described to perform the computational simulation, to establish bounds on interfacial bond strength and to interpret interfacial bond quality.
\end{abstract}

\section{INTRODUCTION}

Bonding phenomena between fiber and the matrix (interfacial) are generally regarded as playing an important role in the mechanical behavior of composite materials in general, and ceramic matrix composites in particular. Bond degradation is often a critical factor in determining the ultimate strength of a composite material, as well as its fatigue resistance, impact resistance and other important properties. The strength of the bonding between fiber and the matrix plays a major role in the ability of the composite to bridge cracks or deflect cracks along the interface, thereby, contributing to the composite fracture toughness (ref. 1). In order for such fracture toughening to occur, the fiber matrix interface must exhibit just the right degree of bonding. If the bonding is too strong, for example, the composite behaves like a monolithic material, as a result cracks propagate through the material and it generally results in brittle fracture.

"Work funded by Space Act Agreement C-99066-G.

tSenior Aerospace Scientist. 
Previous researchers have conducted experiments on ceramic fiber/ceramic matrix composites to estimate shear bond strength and interfacial friction stress. Typically, in these experiments, referred to as pushout tests, free ends of a fiber in a unidirectional composite specimen with a ground and polished surface normal to the fiber axis are subjected to point loads at various temperatures as shown schematically in figure $i(a)$ and (b). The loads required for either interfacial debonding or interfacial sliding are measured and related to interfacial properties. Marshall (refs. 2 and 3) used a conventional Vickers microhardness diamond indenter to depress frictionally bonded SiC fibers in a LAS (11thium aluminosillcate) matrix. Laughner (ref. 4) and Brun and singh (ref. 5) have used slight variation of the above technique to find the fiber pushout load in a composite specimen. Morscher et al. (ref. 6) have studled the interfaclal shear strength of AVCO SCS-6 fiber-reinforced reaction-bonded $\mathrm{Si}_{3} \mathrm{~N}_{4}$ (RBSN) composite as a function of temperature. Fiber pushthrough experiments were conducted with a diamond indenter and a high temperature microhardness tester.

In view of the success of three-dimensional finite element computational simulation of composite micromechanical behavior (ref. 7), it is approprlate and timely to computationally simulate the fiber pushthrough process. The objective of the present report is to describe a computational simulation procedure to simulate the fiber pushthrough process, to identify the dominant parameters in the planning of physical experiments and to interpret results obtained therefrom.

\section{NOMENCLATURE}

E Young's modulus

G Shear modulus

$\ell \quad$ fiber length

P fiber pushout Load

R fiber Radius

Sis-yleld in-situ yield shear strength

T temperature

$T_{C} \quad$ consolidation temperature of the composite

$t_{1}$ thickness (width) of the interface

$u$ fiber displacement at the far end

a coefficient of thermal expansion

$\Phi$ fiber diameter $(=2 . R)$

$\checkmark \quad$ Polsson's ratio

oin. normal stress acting on the interface 
Subscripts

$\begin{array}{ll}\text { m } & \text { fiber } \\ \text { in } & \text { matrix } \\ 11 & \text { interface } \\ 22,33 & \text { is the longitudinal (along the fiber) direction } \\ & \text { are transverse (to the fiber) directions }\end{array}$

FUNDAMENTAL CONCEPT

The concepts adopted to expedite the computational simulation arise from the physics of the fiber pushthrough process and are summarized in this section. The collective results cited in the references indicate that the maximum interfacial shear stress occurs just inside the loaded end of the specimen. Debonding initiates at that location. As the load is increased on the fiber, interfacial fracture progresses until the full fiber length is debonded and the fiber just slides out from the other end. In order for progressive fracture to occur, the local interfacial shear stress must exceed the corresponding strength. As the interfacial bond shear strength is approached, the interfacial shear stiffness decreases rapidly. The process is nonlinear and the full shear stress/strain behavior for the interface bond is generally needed in the simulation. An alternate approach is used, herein, to take advantage of the rapid reduction in shear stiffness. This approach is readily implemented, is computationally effective and to the author' knowledge, it is applied to computationally simulate the interfacial bond fracture for the first time.

A hypothetical shear stress versus shear strain curve for the interface material behavior is shown in figure 2. The curve is initially linear (OA), representing a reversible or recoverable shear deformation upon unloading. As the shear strain increases, progressive nonlinearity ( $A B$ ) occurs, which now includes deformations which are irreversible or unrecoverable. In this region, the instantaneous shear modulus keeps on decreasing. Eventually, the shear modulus becomes almost zero, and the shear strain becomes unbounded, meaning fracture of the interface and the fiber just pushes through. The advantage of the present approach is the use of the approximate magnitude of the shear modulus near point B (fracture load, refer to fig. 2) to estimate the shear stress in the interface at fiber pushout. Hence, a sequence of progressively reduced shear moduli, corresponding to tangent shear moduli (region $A B$ ) are used in the present simulation. Point $B$ ( $f i g .2$ ) represents shear strain in the interface at the fiber pushout. Thus, the load at fiber pushout is kept the same whether the linear material with reduced shear modulus or the real material with its nonlinear behavior is used. In the present work, a linear analysis is done with reduced shear modulus, which substantially simplifies the computational effort and minimizes the tedious calculations that are normally required. A somewhat similar type of procedure is used in the design of civil engineering structures which are subjected to seismic loads (refs. 8 and 9 ).

As mentioned before, the fiber pushthrough process is nonlinear. Hence, in a flber pushout nonlinear simulation, the applied load is increased in small 
Increments until the final fiber pushout load is reached. In the present procedure, this nonlinear process is simulated by replacing the interfacial material with an anisotropic material with reduced shear modulus, and making the simulation process linear up to the pushout load. This type of simulation provides a direct means to estimate the interfacial shear strength in the composite and to determine the stress distribution in the interface region at the instant of fiber pushout. Due to the difference between the consolidation temperature and the use temperature of the composite and also due to the mismatch between the thermal expansion coefficients of fiber and the matrix, there is a residual normal stress acting on the interface. The effect of the normal stress distribution on the interface and on fiber pushout load is readily taken into account as will be explained in the following sections.

The critical interfacial shear stress, and thus, the fiber pushout load is effected by the normal stress acting on the interface. This is in line with an earlier experimental work (ref. 6), which showed that the fiber pushout load does depend upon the temperature at which the flbers are being pushed out.

\section{FINITE ELEMENT MODEL AND SIMULATION PROCEDURE}

The three-dimensional finite element model used in this procedure consists of a group of nine fibers, all unidirectional, in three by three unit cells ("nine cell model") as shown in figure 3. The composite system consists of 0.35 fiber volume ratio SiC/Ti15 metal matrix composite with the properties as shown in table I.

The fiber diameter used is $8.8 \mathrm{mils}(223 \mu \mathrm{m})$. The length to diameter ratio $(\ell / \phi)$ of the model is 6.8 and the thickness (width) of the interface, $t_{1}$, is 6.8 percent of the fiber diameter. The computer code MSC/NASTRAN version 65 (ref. 10) has been used to perform the simulations. A compressive load is applied on the surface of the fiber as described in the different cases below.

For interface, an anisotropic material is assumed (MAT9 property card in MSC/NASTRAN). As mentioned before, for this material, shear modulus $G$ is reduced, thus effecting only the shear stiffness of the interface, where the nonlinearity dominates in the fiber pushout process. The normal stresses to normal strains coefficients in the elasticity matrix are kept same as those for the matrix material. When the load is applied on one end of the fiber, it pushes out from the other end. To define the fiber pushthrough, the following procedure is adopted: a fiber pushthrough test is simulated using the actual materlal properties. In the present model of the specimen, the interface is divided into 16 elements ("bays") along the length (longitudinal direction). Interface material properties are assumed the same as those of the matrix material, except the shear strength of the interface is assumed to be $30 \mathrm{ksi}$, which is approximately 50 percent of matrix shear strength. A compressive load is applied on the flber as shown in figure 1(b). Load is applied gradually and the interface elements are allowed to debond when the shear stress in an element reaches its assumed shear strength. Once, an element is debonded, its shear modulus is reduced to near zero. Debonding progresses gradually along the interface as the applied load is increased. Figure 4 shows the shear stress distribution in the interface as it gradually debonds (load is applied at $X / L=1$ end). Figure 5 shows the applied load versus the fiber displacement at the far end of the specimen. When the interface is completely 
debonded, there is a drop in the load and the fiber just pushes out resisting only the frictional stress. The peak load when the complete fiber is debonded is defined as the fiber pushthrough load. $P$. The shear strain at the far end of the interface at the load - when the interface has just completely debonded, will be used to define fiber pushthrough in the simulations, when the reduced shear modulus of the interface is used. In the case, when the interface is gradually allowed to debond, the pushout load, $P$ comes out to be 56.716 for zero residual stress in the interface. The shear strain at the far end of the interface at fiber pushout is 0.03 ( 3 percent), which corresponds to a relative displacement between fiber and the matrix equal to 0.002 times the fiber diameter, for the thickness of the interface being used. For an interfacial residual stress of $-14 \mathrm{ksi}$ (the normal stress that develops in the interface, when the composite is cooled down from processing temperature to room temperature, $\Delta T=1630^{\circ} \mathrm{F}$ ) and $\mu$ (coefficient of friction) assumed to be 0.2 and 0.4 , the frictional stresses $\left(\mu . \sigma_{i n}\right)$ are $-2.8 \mathrm{ksi}$ and $-5.6 \mathrm{ksi}$ respectively. With these frictional stresses applied, the fiber pushout load comes out to be 62.5 and 67.0 ib respectively, as the interface is gradually allowed to debond. Hence, for the simulations when the pushthrough is linearized by reducing the shear modulus of the interface, the fiber pushthrough is defined when the relative displacement between fiber and the matrix at the far end of the specimen equals 0.002 times the fiber diameter. Once, the fiber pushout load is known, the nominal (average) interfacial shear strength is

$$
\sigma_{S}=\frac{P}{2 \cdot \Pi \cdot R \cdot l}
$$

where $R$ and $\ell$ are fiber radius and length, respectively.

\section{CASES STUDIED, RESULTS/DISCUSSION}

The cases investigated, typical results obtained and their relevance to composite behavior are described in this section.

\section{REFERENCE CASE}

Reference case is defined as the case when the fiber is pushed without residual stresses in the interface, that develop due to fabrication process (about 1700 to $70^{\circ} \mathrm{F}$ for SIC-Til5 metal matrix composite). Specifically, it is assumed that the composite is free from any residual thermal stresses that develop due to thermal expansion coefficient mismatch between fiber and the matrix. The fiber pushout load, $P$, is found from finite element simulations as the shear modulus, $G$, of the interface varies. As mentioned before, the fiber pushout is defined at the load when relative displacement between the fiber and matrix at the far end equals 0.002 times the fiber diameter. The fiber pushout load, $P$, versus the shear modulus of interface, is shown in figure 6 . The pushout load varies nonlinearly with shear modulus below 0.3 mpsi (approximately) and linearly above this value. This may be interpreted to mean that the pushout load varies linearly for strong interfacial bond and nonlinearly for weak interfacial bond. It should be mentioned once again, that an anisotropic material has been used for the interface such that the coefficients in the elasticity matrix for normal stress - normal strain are the same as those for the matrix material. Only, the shear modulus, $G$, of the interface material has been reduced, making it rather soft in shear. For the fiber pushout load 
of $56.7 \mathrm{lb}$, the value of $G$ turns out to be $330 \mathrm{ksi}$ or $0.33 \mathrm{mpsi}$. The average shear stress on the interface, $\sigma_{s}$ computed from equation (1), comes out to be $33.8 \mathrm{ksl}$. For this case, $G \cong 10 \sigma_{\mathrm{s}}$. This provides an initial estimate for $G$ of about 10 times the interfacial fracture shear stress (or reduced matrix yield stress) to be used in the computational simulation.

\section{TEMPERATURE EFFECTS ON FIBER PUSHOUT LOAD}

As the composite is cooled down to temperatures lower than consolidation temperature (or reference temperature - assumed to be the stress free state), some residual normal stresses $\left(\sigma_{i n}\right)$ wlll develop in the interface region. These residual stresses may be tensile or compressive. The magnitude of these stresses depends upon the difference between the reference (consolidation) and use temperatures and extent of $\alpha$ mismatch between fiber and the matrix. For example, at higher temperatures close to consolidation temperature, the thermal stresses wlll be low, but at room temperature, when $\Delta T$ is large, these thermal stresses are significant.

In the simulation procedure, it is assumed that the effective shear modulus of the interface can be modified to include the effect of the thermal stresses as follows:

$$
G=G_{0 \pm}\left(\mu \cdot \sigma_{i n}\right) \cdot F
$$

where $\mu$ is the coefficient of friction between the fiber and the matrix materials, oin is the interfacial normal stress, $G_{O}$ is the effective shear modulus at zero interfacial normal stress and $F$ is a scaling factor. Equation (2) is shown graphically in figure 7 . If the normal stress acting on the interface is compressive, it will result in higher shear resistance (interlocking) between the rough surface of the fiber and the matrix and, thus, will result in higher load needed to push the fiber through. This is reflected in figure 7 as follows: compressive normal stresses will mean a higher $G$, which in turn means a higher pushthrough load $(f i g .6)$. In equation (2), Go reflects mainly chemical adhesion between fiber and the matrix as well as mechanical interlocking between rough surface of the fiber and the matrix from shrinkage stresses that develop due to the phase change during the processing of the composite. The normal stress, oin. is mainly due to thermal expansion mismatch. From the simulation, where the interface is gradually allowed to debond, we know the fiber pushout load for a given value of $\sigma$ in and assumed values of $\mu$. Then, by using equation (2) and $P$ versus $G$ curve, the value of $F$ has been found to be $\sim 10.0$ from

$$
\frac{G-G_{0}}{\mu \cdot \sigma_{\ln }}=F
$$

The normal stress on the interface versus the temperature is shown in figure 8. The consolidation temperature is taken as $1700^{\circ} \mathrm{F}$. As seen in figure 8 , the variation of normal stress versus the temperature is almost linear. The normal stress in the interface at consolidation temperature is approximately $-1.0 \mathrm{ks} 1$ (compressive) as shown in figure 8 . 
For a given temperature, the interfacial normal stress is known from figure 8. Then, for a given value of $\mu$ and $G_{0}$ ( $F$ assumed to be 10.0), we calculate $G$ from equation (2), which in turn, gives us a pushthrough load from figure 6 . Thus, the pushthrough load is implicitly a function of temperature. Figures $9(a)$ and $(b)$ show pushthrough load, $P$, versus $G_{0}$ for different values of temperatures and $\mu$. The effect of $\mu$ at consolidation temperature is small (because $\sigma_{i n}$ is small) and hence neglected. An average curve for consolidation temperature $\left(T_{C}\right)$ is, therefore, adopted.

Figures $g(a)$ and (b) are proposed to be used with experiments as follows: first, we conduct a pushthrough test at some temperature near the consolidation temperature and knowing the pushthrough load, determine $G_{0}$. Then, conduct a pushthrough experiment at temperature $T_{1}$ and knowing the pushthrough load at $\mathrm{T}_{1}$, determine the other parameter $(\mu)$ of the model. It has been assumed, so far, that $\mu$ and $G_{O}$ remain constant over a wide range of temperatures, even though, the real material shear modulus might show dependence upon the temperature. If one conducts several pushthrough tests at different temperatures, a regression technique like "least square method" can be used in conjunction with equation (2) to find the "best fitting" values of $\mu$ and $G_{O}$. Then, it will also be clear whether $\mu$ and $G_{0}$ were indeed independent of temperature or not.

Once, values of $\mu$ and $G_{0}$ are determined, for any given temperature one can predict fiber pushthrough load using figure 9 . One can determine the average interfaclal shear strength, since the interfacial normal stress is known as a function of temperature, the part of interfacial shear strength that comes from frictional stresses can be separated. As shown in figure $g(b)$, the fiber pushthrough load at room temperature, depending upon the value of $\mu$, can be 20 to 30 percent higher than the pushout load at consolidation temperature.

For comparison, in the experiments conducted by Morscher et al. (ref. 6), where they used SIC-RBSN composite $\left(\alpha f, \alpha_{m}\right)$, fiber pushthrough load at consolidation temperature was twice the pushthrough load at room temperature. They also reported that most of the failures occurred at carbon-carbon interface within the cellular fiber itself, which exhibited very weak intercellular bonding. In our case, $\alpha_{m}>\alpha_{f}$, hence pushout loads at room temperature are higher than the pushout ioad at consolidation temperature. The shear strength of the interface has been assumed to be $30 \mathrm{ksi}$. If the interface shear strength is lower, then the percent of increase in pushout load at room temperature will be greater for the same value of $\mu$.

\section{PROCEDURE FOR ESTIMATING THE PUSHOUT LOAD}

The collective results from the computation simulations previously described can be used to provide step-by-step procedures for: (1) computationally simulating interfacial bond, (2) establishing upper and lower bounds on the pushout load, and (3) providing some guidelines for assessing conditions at the interface. The terms to be used in the subsequent development are defined for clarity.

\section{Term Definition}

Perfect Interface Bond - The matrix fractures in shear. The surface of the pushed-out fiber is covered with a layer of matrix material. No bare fiber surface is exposed. 
No Interfaclal Bond - The surface of the pushed-out fiber is bare and clear of any matrix residue.

Strong Interfactal Bond - The surface of the pushed-out fiber has substantial matrix residue.

Weak Interfacial Bond - The surface of the pushed-out fiber has sparsely distributed matrix residue.

\section{Strong Interface Bond}

The pushout load for strong interfacial bond is simulated as follows:

(1) Obtain the room temperature properties of the fiber and the matrix (constituent) materials and the processing conditions.

(2) Generate a three-dimensional finite element model as described in the finite element model and simulation procedure section.

(3) Perform the simulation described in the same section as in item (2) above assuming that the interface fractures when the shear stress reaches the shear yield stress.

(4) Find the pushout load when the fiber at the far end advances about 0.2 percent of the fiber dlameter. This usually occurs near the peak load of the load versus far end displacement curve.

(5) This is the upper bound of the interfacial bond strength indicating perfect bond at the interface as previously defined. Composites approaching this value have near perfect bond at the interface and were manufactured by the best quality possible for interfacial bond.

\section{No Interface Bond}

The pushout load for little (negligible) or no interfaclal bond is simulated as follows:

(1) Same as for strong interface bond.

(2) Same as for strong interface bond.

(3) Determine the thermal (normal) stresses $\left(\sigma_{i n}\right)$ at the interface using finite element analysis.

(4) Estimate the equivalent shear modulus from:

$$
G_{e} \simeq \mu \cdot \sigma_{i n} \cdot F
$$

with $\mu \cong 0.5$ and $F \cong 10$.

(5) Perform the simulation procedure described in the temperature effects on fiber pushout load section with $G=G_{e}$ from step (4) above. 
(6) Determine the pushout load as the load needed to advance the fiber by 0.2 percent of flber diameter at the far end. Composites exhibiting this type of pushout load have no interface bond and anything that can be done to improve it is worth the effort.

\section{INITIAL ESTIMATES ON INTERFACIAL BOND}

Initial estimates for strong and no interface bond can be obtained from the curves presented herein as follows:

\section{Strong Interface Bond}

(1) Estimate yield shear stress of the matrix (Sis-yleld).

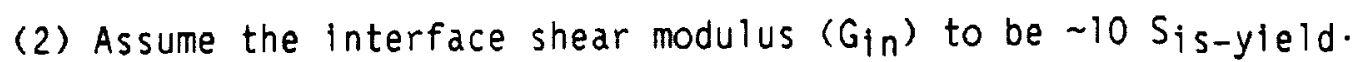

(3) With this value of $G_{i n}$, determine the pushout load from figure 6 .

(4) For example: graphite/copper composite

$$
S_{i s-y i e l d} \cong 5 \mathrm{ksi} ; G_{i n}=10 \times 5=50 \mathrm{ksi}=0.05 \mathrm{mpsi}
$$

Pushout load, $P$ from figure $6 \cong 5 \mathrm{lb}$.

\section{No Interface Bond}

(1) Determine the product $\Delta \alpha \cdot \Delta E \cdot \Delta T$ for the composite of interest, where $\Delta \alpha$ and $\Delta E$ are differences in the $\alpha$ and $E$ between the fiber and the matrix respectively. This gives an estimate of the thermal normal stress in the interface. $\Delta T$ is the difference between the processing and operating temperatures.

(2) Determine the product $\Delta \alpha \cdot \Delta E \cdot \Delta T$ for the composite in section on temperature effects on fiber pushout load ( $\mathrm{SiC} / \mathrm{Ti} i 5)$.

(3) Determine the equivalent shear modulus $\mathrm{Ge}_{e}$ for Sic/Til5 composite from equation (2):

$$
G_{e}=\mu \cdot \sigma_{i n} \cdot F \quad\left(G_{0} \cong 0\right)
$$

e.g., $\Delta T=1630^{\circ} \mathrm{F}, \mu=0.5, F=10$, from figure $8, \sigma$ in $=14 \mathrm{ksi}$

then, $G_{e}=0.5(14 \mathrm{ksi}) 10=70 \mathrm{ksi}=0.07 \mathrm{mpsi}$

(4) Determine the corresponding pushout load from figure 6:

$$
p \simeq 101 \mathrm{~b}
$$

(5) Determine the ratio of products in steps (1) and (2). 
(6) Adjust the pushout load in step (4) by the ratio in step (5). This is the required pushout load for the composite of interest.

(7) For example:

For graphite/copper composite,

$\Delta \alpha \cdot \Delta \mathrm{E} \cdot \Delta \mathrm{T}=\left(4 \times 10^{-6}\right) \cdot\left(9 \times 10^{6} \mathrm{psi}\right) \cdot\left(1730^{\circ} \mathrm{F}\right)$

For $\mathrm{SIC} / \mathrm{Ti} 15$ composite,

$\Delta \alpha \cdot \Delta E \cdot \Delta T=\left(2.7 \times 10^{-6}\right) \cdot\left(49.7 \times 10^{6} \mathrm{psi}\right) \cdot\left(1630^{\circ} \mathrm{F}\right)$

Then, the ratio is:

$$
\frac{\left(4 \times 10^{-6}\right) \cdot\left(9 \times 10^{6}\right) \cdot\left(1730^{\circ} \mathrm{F}\right)}{\left(2.7 \times 10^{-6}\right) \cdot\left(49.7 \times 10^{6}\right) \cdot\left(1630^{\circ} \mathrm{F}\right)}=0.285
$$

The corresponding pushout load is then,

$$
P=0.285 \times 10=2.851 \mathrm{~b}
$$

a relatively small value. Improved estimates can be obtained when composite micromechanics is used to calculate the interfacial normal stresses (refs. 11 and 12 ). The authors recommend that the user estimate the bounds of the interfacial strength for $h$ is composite(s) of interest in order to become familiar with the relative ease in applying these procedures.

The range between the two bounds on fiber pushout load for Gr/Cu composite is about 2.85 to $5.01 \mathrm{~b}$. The corresponding range for $\mathrm{SiC} / \mathrm{Til} 5$ composite is 10 to $100 \mathrm{ib}$. As can be seen, the bounds for the $\mathrm{Gr} / \mathrm{Cu}$ composite are relatively close while those for the SiC/Tils composite are relatively far apart. These simple calculations show that there is not much that can be done to increase the fiber pushout load in $\mathrm{Gr} / \mathrm{Cu}$ composite by manipulating the interfacial conditions. On the other hand, the pushout load for the SiC/Tils composite can be substantially increased by increasing the bond strength at the interface. Another way to look at it is that $\mathrm{Gr} / \mathrm{Cu}$ composites are rather insensitive to quality control of the interfacial conditions while SiC/Tils composites are not.

Weak interfacial bond can be computationally simulated by following the same procedures for the strong bond. However, for this case the interfacial elements are assigned different in-situ yleld shear strength ( $S_{i s-y j e l d}$ ) values, ranging from 0 to that of the matrix; or respective shear moduli for the initial estimates (ref. 13).

\section{GENERAL REMARKS}

Though the results are not included here, the following observations were made during the course of the present work:

(1) Whether the whole or part of the fiber surface is loaded, the total load required for fiber pushout remains the same. Stress distributions in the interface have also remained the same indicating negligible poisson ratio effect. 
(2) The fiber pushout load is independent of the number of fibers loaded simultaneously. The normal stress distribution in the interface is also independent of whether one or several fibers are being pushed through. This suggests negligible fiber interaction, at least for the composite system and the fiber volume ratio investigated.

(3) Normally, the fibers are pushed by an indenter. One has to ensure that the tip diameter of the indenter is smaller than the fiber diameter, so that while indenting the fiber, it should not push against the matrix.

\section{SUMMARY}

A computational simulation procedure has been developed to simulate the fiber pushthrough process. The procedure consists of three-dimensional finite element simulation method with a unique representation of the interfacial shear stress behavior. The interface material has been replaced by an anisotropic material with greatly reduced shear modulus in order to simulate the fiber pushthrough process using a linear analysis. This procedure can be used to predict fiber pushthrough load for a composite system at any temperature. The average interfacial shear strength and its component two parts - one that comes from frictional stress (due to normal stress) and the other that is due to chemical adhesion, rough fiber surfaces and the stresses that develop due to the phase change during the processing of the composite, can be obtained. For the composite system used, the fiber pushout load is 20 to 30 percent higher than the fiber pushout load at consolidation temperature, due to higher frictional stresses. Step-by-step procedures are described to perform the computational simulation, establish bounds on fiber pushout load and to interpret the interfacial bond quality.

\section{REFERENCES}

1. Marshal1, D.B.; and Evans, A.G.: Fallure Mechanisms in Ceramic-Fiber/ Ceramic-Matrix Composites, J. Am. Ceram. Soc., vol. 68, no. 5, May 1985, pp. 225-231.

2. Marshal1, D.B.: An Indentation Method for Measuring Matrix-Fiber Frictional Stresses in Ceramic Composites. J. Am. Ceram. Soc., vol. 67, no. 12, Dec. 1984, pp. C259-C260.

3. Marshall, D.B.; and Oliver, W.C.: Measurement of Interfacial Mechanical Properties in Fiber-Reinforced Ceramic Composites. J. Am. Ceram. Soc., vol. 70 , no. 8, Aug. 1987, pp. 542-548.

4. Laughner, J.W., et al.: Simple Indentation Method for Measurement of Interfacial Shear strength in $\mathrm{SiC} / \mathrm{Si}_{3} \mathrm{~N}_{4}$ Composites. Ceram. Eng. Sci. Proc., vol. 7, no. 7-8, July-Aug., 1986, p. 932.

5. Brun, M.K.; and Singh, R.N.: Effect of Thermal Expansion Mismatch and Fiber Coating on the Fiber/Matrix Interfacial Shear Stress in Ceramic Matrix Composites. Adv. Ceram. Mater., vol. 3, no. 5, 1988, pp. 506-509. 
6. Morscher, G.; Pirouz, P.; and Hever, A.H.: Temperature Dependence of Interfacial Shear Strength in SiC-Fiber-Reinforced Reaction-Bonded Silicon Nitride. J. Am. Ceram. Soc., vol. 73, no. 3, Mar. 1990, pp. 713-720.

7. Mital, S.K.; Caruso, J.J.; and Chamis, C.C.: Metal Matrix Composites Microfracture: Computational Simulation. Accepted as Invited Paper for Presentation at the Symposium on Computational Technology for Flight Vehicles, Nov. 5-7, 1990, Washington, D.C.

8. Shibata, A.; and Sozen, M.A.: Substitute-Structure Method For Seismic Design in R/C. J. Struct. Div., ASCE, vol. 102, no. ST1, Jan. 1976, pp. $1-18$

9. Mital, S.K.: Pseudo Non-Linear Seismic Analys is For Damage Evaluation of Concrete Structures. Master's Thesis, The University of British Columbia, Vancouver, Canada, May 1985.

10. MSC/NASTRAN, User's Manual, Version 64, Vol. I and II. The MacNeal Schwendler Corporation, Los Angeles, 1984.

11. Murthy, P.L.N.; Hopkins, D.A.; and Chamis, C.C.: Metal Matrix Composite Micromechanics: In-Situ Behavior Influence on Composite Properties. NASA TM-102302, 1989.

12. Caruso, J.J.; Chamis, C.C.; and Brown, H.C.: Parametric Studies to Determine the Effect of Compllant Layers on Metal Matrix Composite Systems. NASA TM-102465, 1990.

13. Caruso, J.J.; Trowbridge, D.; and Chamis, C.C.: Finite Element Applications to Expiore the Effects of Partial Bonding on Metal Matrix Composite properties. NASA TM-101482, 1989.

TABLE 1. - PROPERTIES OF CONSTITUENT MATERIALS OF SIC/Ti15

\begin{tabular}{|c|c|c|c|}
\hline & SiC fiber & Tils Matrix & Interface \\
\hline Modulus, E (mpsi) & 62.0 & 12.3 & 12.3 \\
\hline Poisson's ratio, $v$ & 0.3 & 0.32 & 0.32 \\
\hline Shear modulus, $G$ (mpsi) & 23.8 & 4.6 & $\begin{array}{l}\text { varies from } \\
0 \text { to } G_{\text {matrix }}\end{array}$ \\
\hline $\begin{array}{r}\text { Coefficient of thermal } \\
\text { expansion } \alpha\left(\mathrm{ppm} /{ }^{\circ} \mathrm{F}\right)\end{array}$ & 1.8 & 4.5 & 4.5 \\
\hline
\end{tabular}




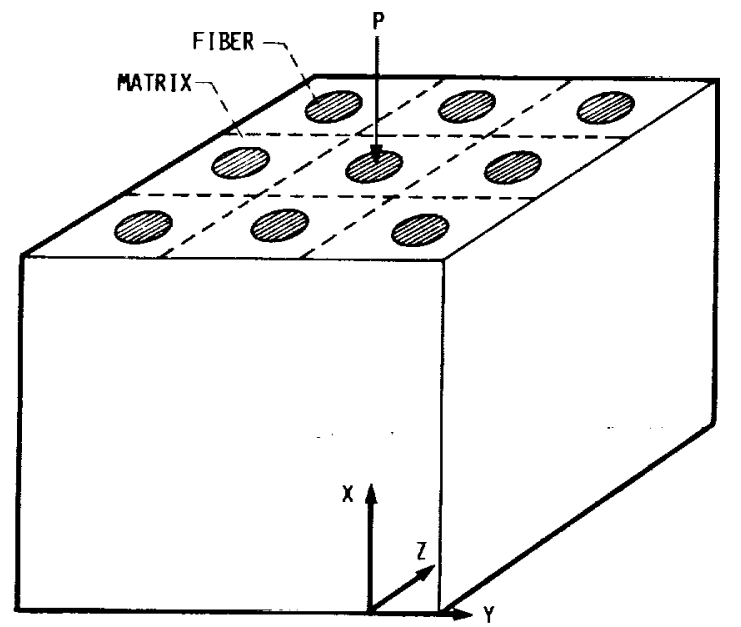

(a) FIBER PUSH-OUT.

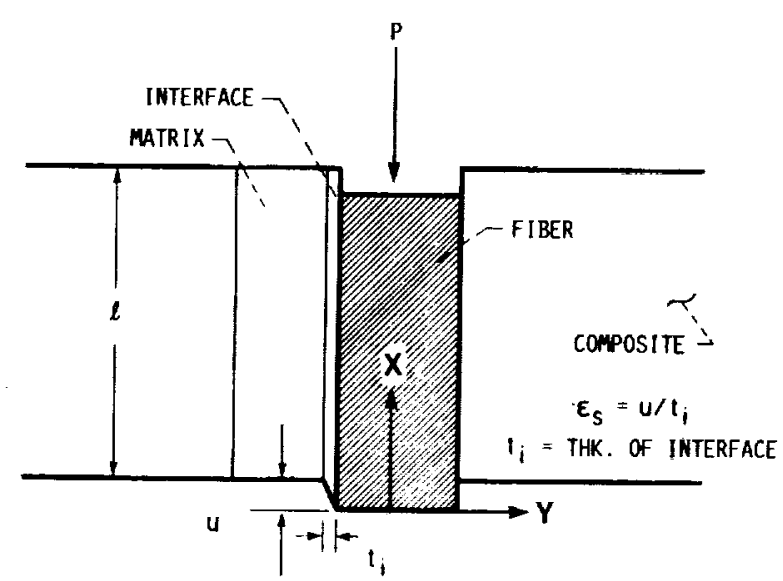

(b) FIBER PUSH-THROUGH.

FIGURE 1. - SCHEMATIC REPRESENTATION OF FIBER PUSH-OUT AND PUSH-THROUGH TECHNIQUES.

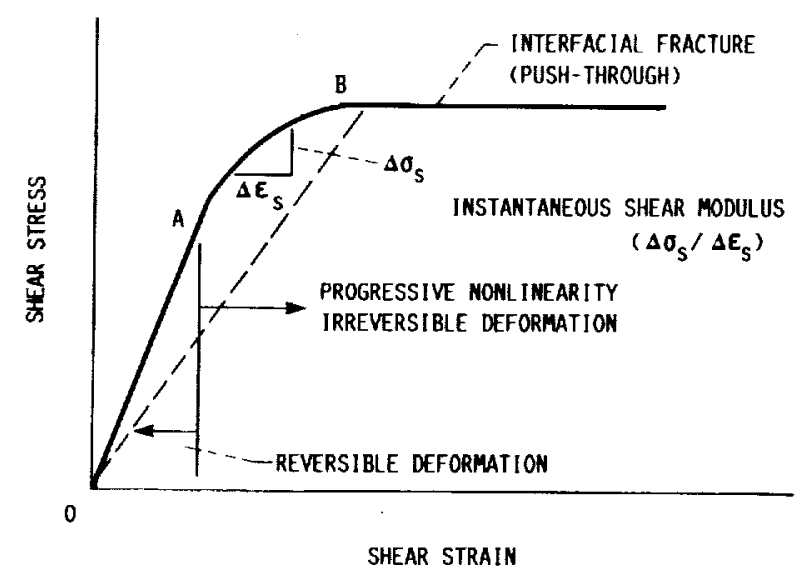

FIGURE 2. - SHEAR STRESS VERSUS SHEAR STRAIN CURVE FOR THE MATRIX MATERIAL. 


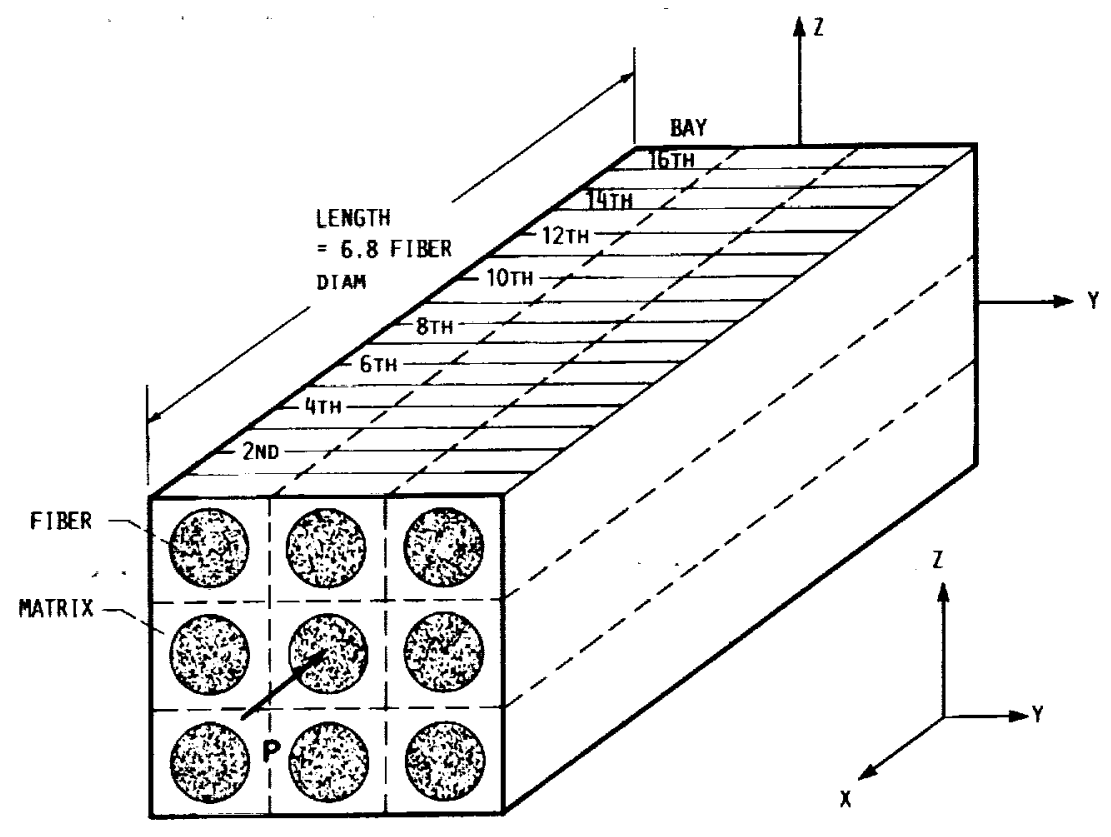

FIGURE 3. - REPRESENTATION OF NINE CELL MODEL. 

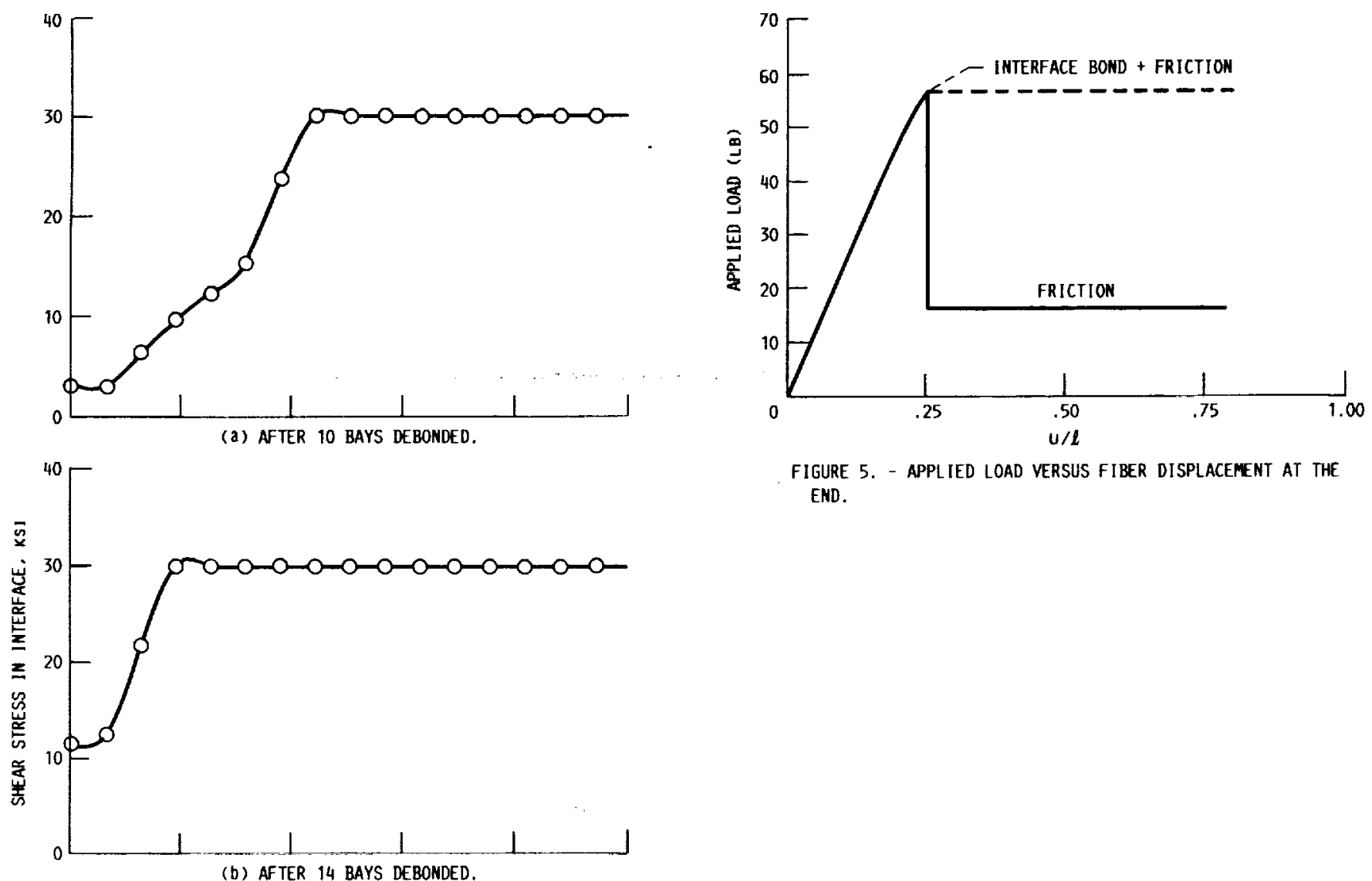

FIGURE 5. - APPL IED LOAD VERSUS FIBER DISPLACENENT AT THE END.

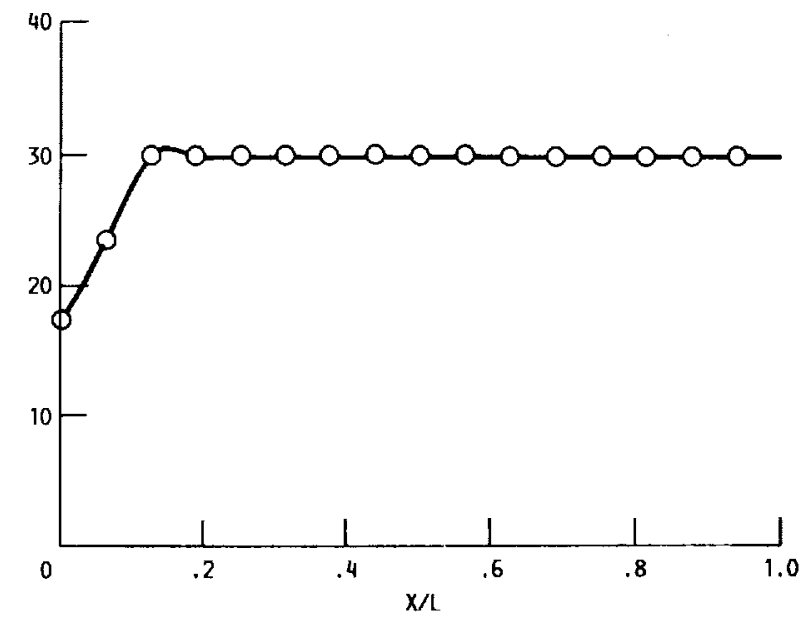

(C) AFTER T5 BAYS DEBONDED.

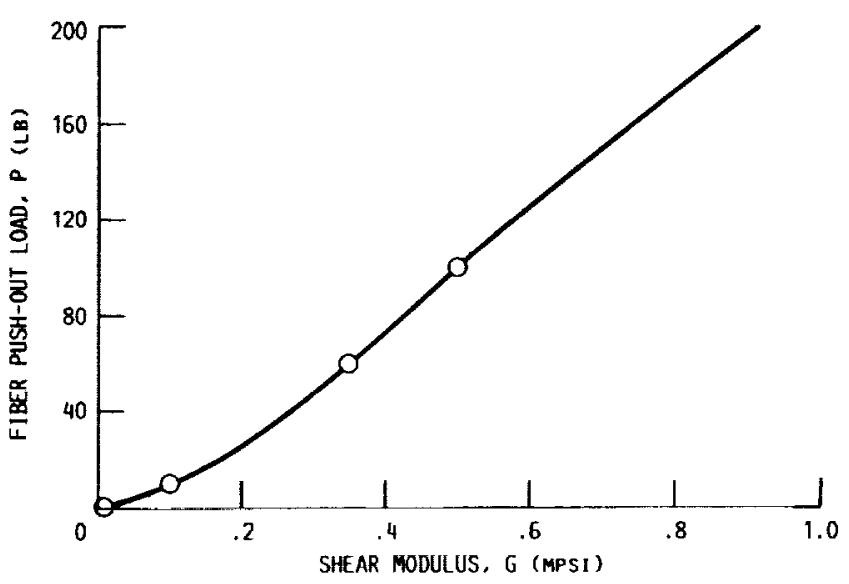

FIGURE 4. - SHEAR STRESS DISTRIBUIION IN THE INTERFACE.

FIGURE 6. - VARIATION OF FIBER PUSH-OUT LOAD VERSUS SHEAR MODUL US OF INTERFACE. 


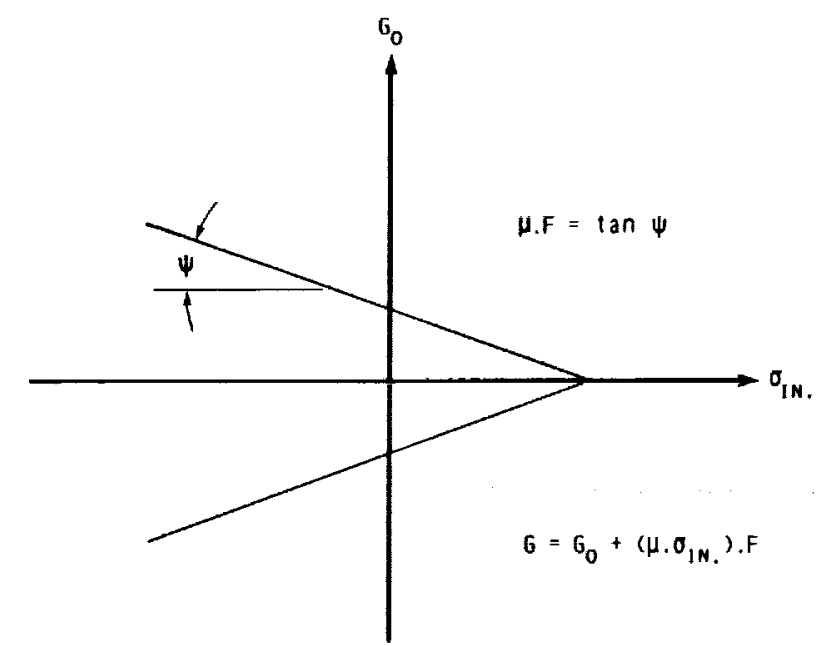

FIGURE 7. - REPRESENTATION OF EFFECTIVE SHEAR MODULUS OF INTERFACE MATERIAL.

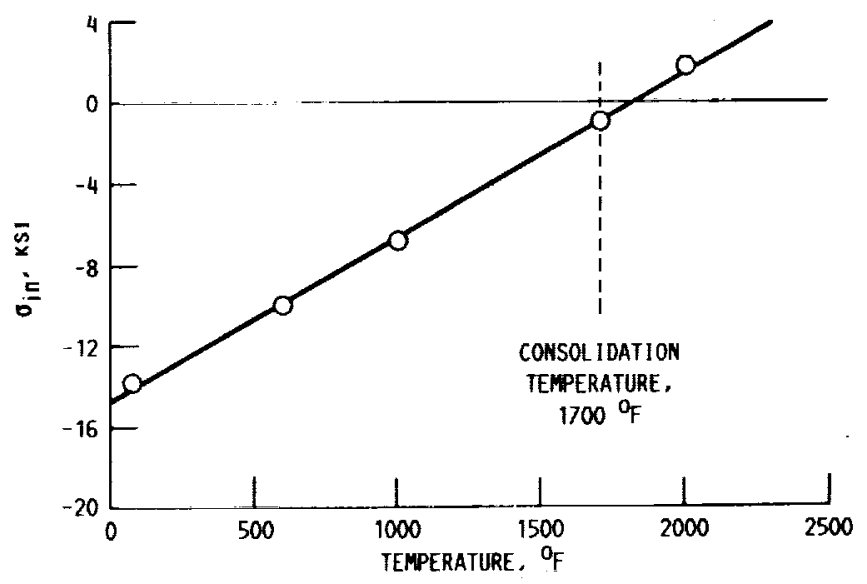

FIGURE 8. - VARIATION OF NORMAL INTERFACIAL STRESS VERSUS TEMPERATURE

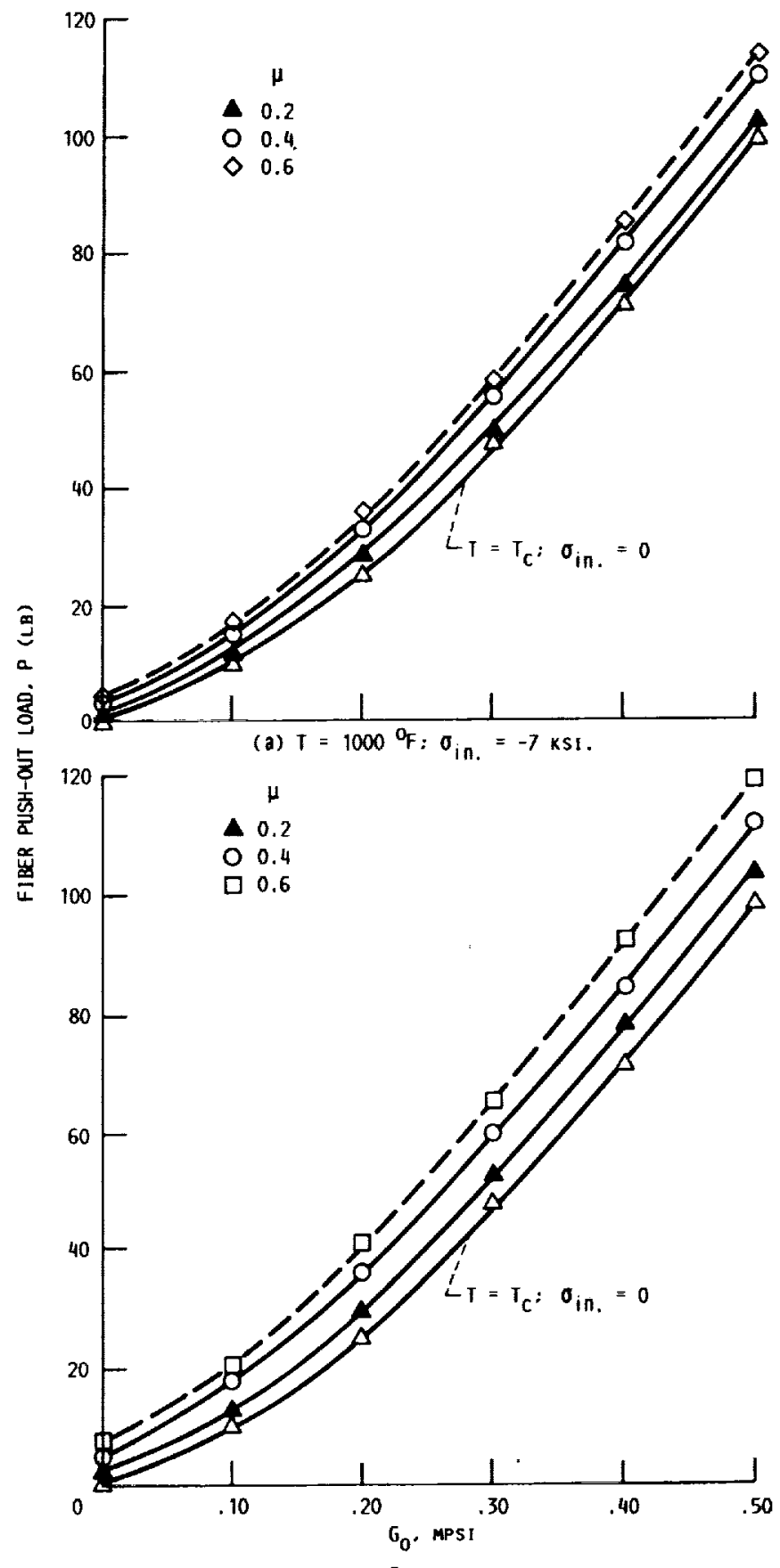

(b) $\mathrm{T}=70^{\circ} \mathrm{F}: \sigma_{\mathrm{in},}=-14 \mathrm{ksI}$.

FIGURE 9. - FIBER PUSH-OUT LOAD VERSUS $G_{0}$. 


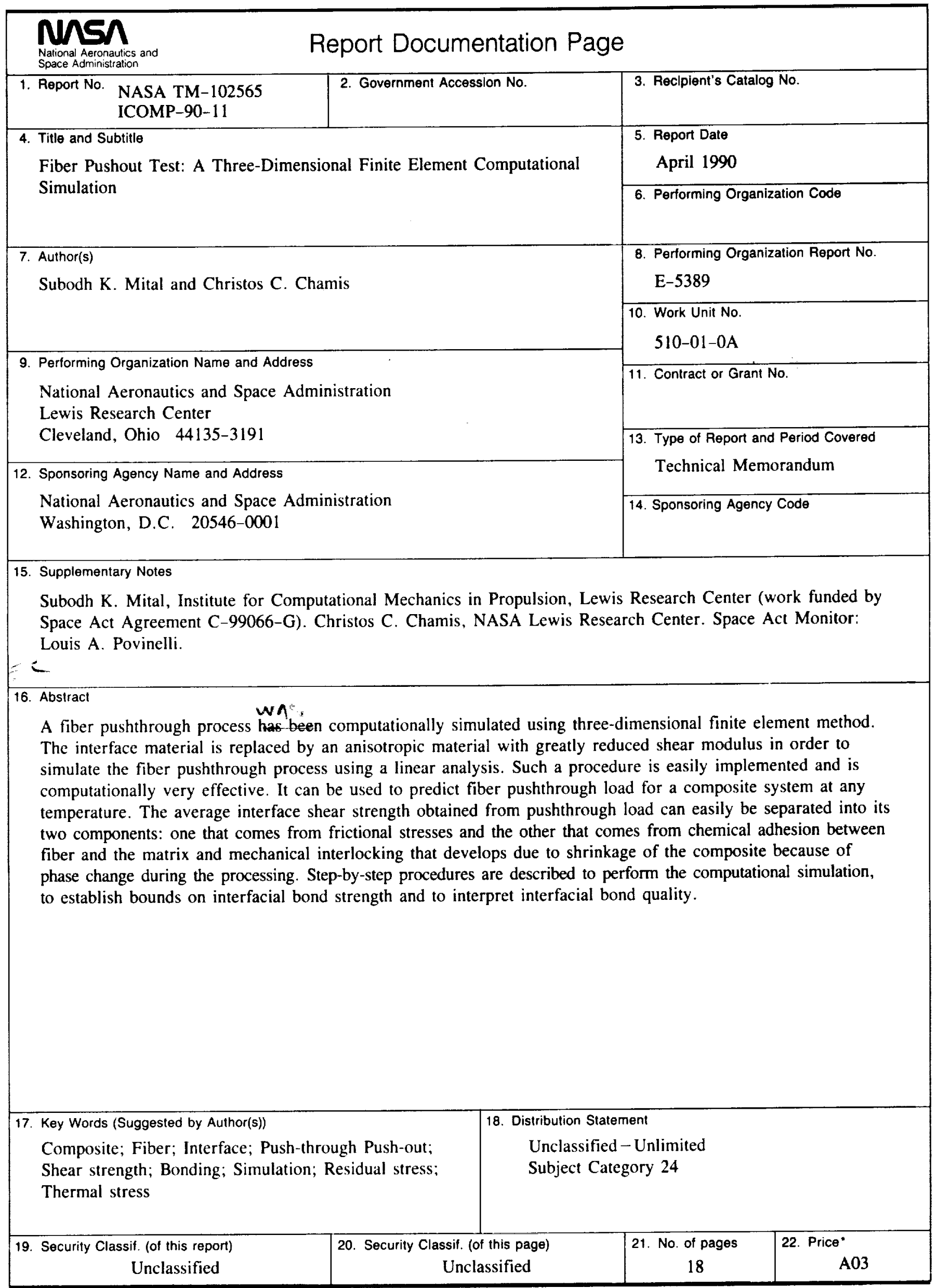




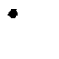

